\title{
Seismic Site Specific Study for Seismic Microzonation: A Way Forward for Risk Resiliency of Vital Infrastructure in Sikkim, India
}

\author{
0. P. Mishra1,2*, Priya Singh1, B. Ram², Sasi Kiran Gera1, O. P. Singh ${ }^{2}$, K. K. Mukherjee2,3, \\ G. K. Chakrabortty ${ }^{2,4}$, S. V. N. Chandrasekhar ${ }^{2,5}$, A. Selinraj ${ }^{2,6}$, S. K. Som ${ }^{7,8}$ \\ ${ }^{1}$ National Centre for Seismology, Ministry of Earth Sciences, New Delhi, India \\ ${ }^{2}$ Geophysics Division, DRPC-Geological Survey of India (CHQ), Kolkata, India \\ ${ }^{3}$ Geophysics Division, NER-Geological Survey of India, Shillong, India \\ ${ }^{4}$ ERO-Geological Survey of India, Kolkata, India \\ ${ }^{5}$ SRO-Geological Survey of India, Hyderabad, India \\ ${ }^{6}$ RSS-Geological Survey of India, Bangalore, India \\ ${ }^{7}$ NER-Geological Survey of India, Sikkim, India \\ ${ }^{8}$ GHRM Centre, Geological Survey of India (CHQ), Kolkata, India \\ Email: ${ }^{\star}$ omp.mishra@nic.in
}

How to cite this paper: Mishra, O.P., Singh, P., Ram, B., Gera, S.K., Singh, O.P., Mukherjee, K.K., Chakrabortty, G.K., Chandrasekhar, S.V.N., Selinraj, A. and Som, S.K. (2020) Seismic Site Specific Study for Seismic Microzonation: A Way Forward for Risk Resiliency of Vital Infrastructure in Sikkim, India. International Journal of Geosciences, 11, 125-144.

https://doi.org/10.4236/ijg.2020.113008

Received: December 26, 2019

Accepted: March 28, 2020

Published: March 31, 2020

Copyright (c) 2020 by author(s) and Scientific Research Publishing Inc. This work is licensed under the Creative Commons Attribution International License (CC BY 4.0).

http://creativecommons.org/licenses/by/4.0/ (c) (i) Open Access

\begin{abstract}
Seismic Microzonation comprising study of site specific seismic Microtremor ( $H / V$ ratio) is deployed to generate seismological parameters (Peak Frequency, Peak Amplification, Site Vulnerability Index) that may help estimate requisite factors for sound building design codes that can be used to construct risk resilient infrastructures. In this paper the site of Pakyong, Sikkim, India has been investigated by dividing it into three differed zones (Zone 1, Zone II, Zone III). The study area is associated with site amplification factor varying from 1.47 to 11.49 with corresponding frequency variations from $0.5 \mathrm{~Hz}$ $12.5 \mathrm{~Hz}$ in which site vulnerability index found varied from 0.2 to 220.6. The anomalous subsurface formation with its high amplification corresponds to the centre of the Pakyong sites having conspicuous trend in NW-SE direction suggesting the existence of geological formations of Chlorite, Phyllite with intercalations of Quartzite beneath the centre of Pakyong site. The risk associated with vulnerability index for different zones maintains its variability as Zone I $>$ Zone II $>$ Zone III, indicating the low vulnerability index values are attributed to compact parts of the sub-surface materials with less amplifications whilst high vulnerability index of the site corresponds to relatively lower strength of the sub-surface materials and soft sediments underlying the Pa-
\end{abstract}


kyong site which can be used for constructing risk resilient structure by enhancing the stiffness coefficient of the sub-surface by providing plausible engineering solutions for the purpose.

\section{Keywords}

Seismic Site Specific, Seismic Microzonation, Risk Resilient, $H / V$ Ratio, Peak Amplification, Peak Frequency, Site Vulnerability Index, Stiffness Coefficient

\section{Introduction}

With rapid demand for infrastructural facilities, it has become necessary and warranted to develop risk-resilient infrastructures, which may augment to the plan of development of smart city in India. In this study, site specific seismological investigations were conducted for estimating key seismological parameters responsible for earthquake hazards in the area by deploying site response study in and around Pakyong, Sikkim $\left(27.20^{\circ} \mathrm{N}\right.$ to $27.25^{\circ} \mathrm{N} ; 88.56^{\circ} \mathrm{S}$ to $\left.88.61^{\circ} \mathrm{S}\right)$ for development of infrastructures in the area. Under the plan of smart city development of India, airport development and its safety design parameters have become a challenging issue to geoscientific and civil engineers. Seismic microzonation involves the assessment of the local site effects by calculating the site amplification and corresponding predominant frequency. It is an important technique in Seismic Hazard assessment and risk evaluation and is defined as the zonation with respect to ground motion characteristics taking into account the source and site conditions. It is a technique of dividing an earthquake prone region into individual areas having different potential hazardous earthquake effects based on the seismic behaviour of local site [1] [2]. Site response study mainly deals with the determination of peak frequency $\left(f_{0}\right)$ of soil and their corresponding, amplification which forms an important input for evaluating and characterizing the impact of ground motion on shaking of grounds and degree of damages vis-à-vis estimating the site vulnerability. Pakyong is a town in the foothills of the Himalayas located in the East Sikkim district of the Sikkim state (Figure 1). Critical infrastructures facilities, such as, green field airport, hospitals, schools, vital installations can be developed using the concept of risk resiliency of the structutres in the site of Pakyong. A green field airport at Pakyong, Sikkim was then proposed with a dimension of approximately $2000 \mathrm{~m}$ length $\times 500 \mathrm{~m}$ width. The main objective of site response survey in this area is to assess the site vulnerability in and around Pakyong, covering an area of $25 \mathrm{sq} \cdot \mathrm{kms}$.

The area of study is associated with Gorubathan formation of Daling Group represented by low grade metapelitic rocks, mainly comprising Phyllite and Schists with thin intercalations of Quartzites belonging to the main litho units in and around Pakyong area. Our area of interest mainly belongs to Main Central Thrust (MCT) which separates Sedimentary and Low grade Metamorphics of Lesser Himalaya from Crystalline rocks of Higher Himalaya (Figure 1). The 


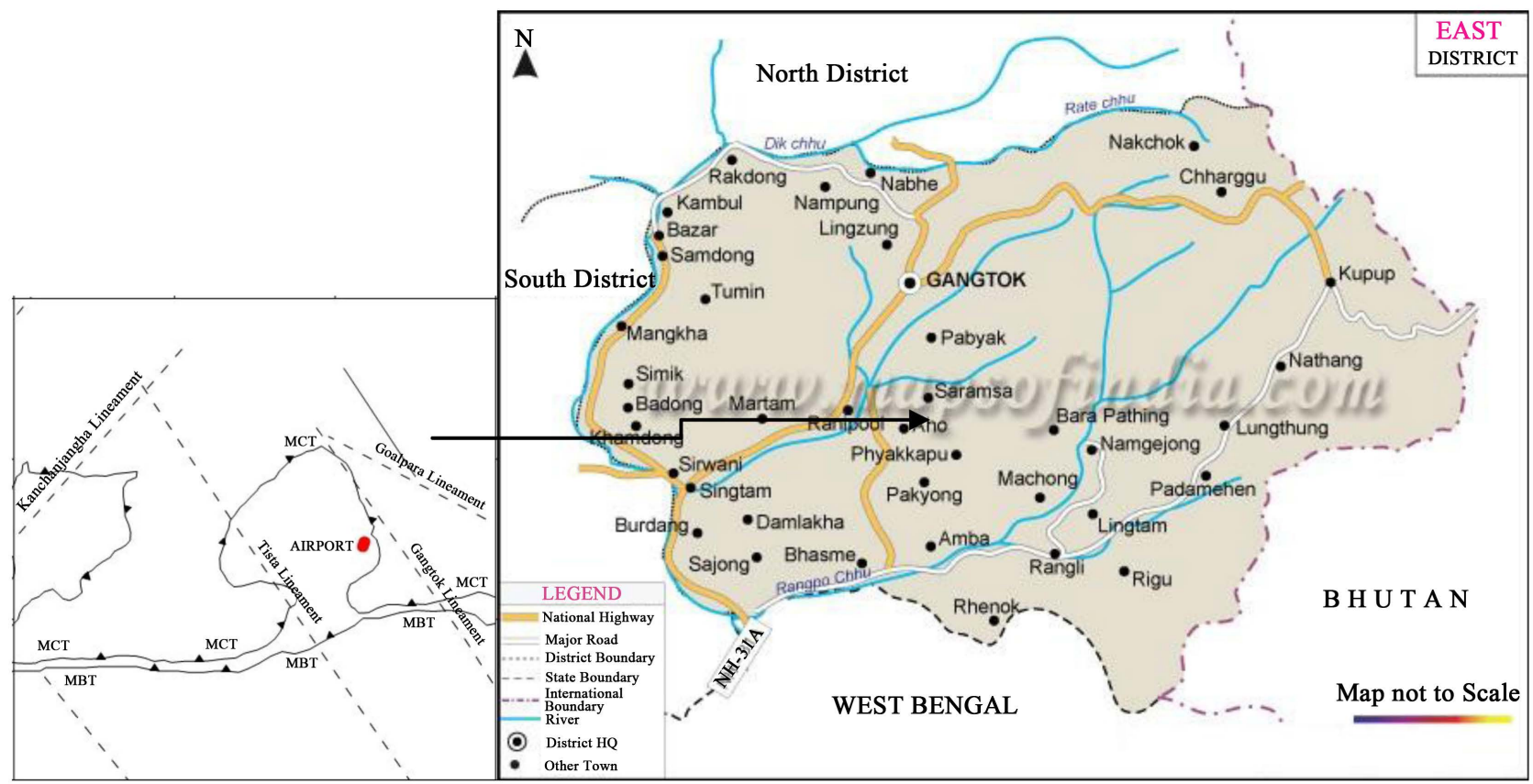

Figure 1. District map of east Sikkim with location of the Pakyong airport, Sikkim (red mark) (adapted from the report by [3]).

Sikkim region is located in the earthquake prone territory of the eastern Himalaya. It is evident from the earthquake zonation map of India that the Sikkim Himalaya comes under high seismic hazard zone designated as Zone IV (IS1893, Bureau of Indian Standards, 2002). The Sikkim region is surrounded by several damaging earthquakes of the past, although it has not experienced a magnitude 8.0 earthquake so far. The region has only experienced moderate seismicity in the past. The two strong earthquakes of magnitude greater than 6.0 were recorded in 1965 \& 1980 and then were reported for the Sikkim Himalaya. The seismic hazards scenario of Sikkim Himalaya appears to be quite underestimated considering its zone IV status in the seismic zonation map of India. On $18^{\text {th }}$ September 2011 an earthquake ( $\mathrm{Mw}$ 6.9) occurred in NW Gangtok, Sikkim at approximately $60 \mathrm{~km}$ distance near the boundary between the India and Eurasian plates in the mountainous region of northeast India in Sikkim-Nepal border region. Nearly 97 people were reported died and several people were injured during the earthquake [3].

The location of study area is shown in Figure 1, which falls under East Sikkim district and is well connected by metal road. The field site's accessibility is limited and is from Ranipool located at the distance of $18 \mathrm{~km}$ as well from Rangpo from where the study area is $26 \mathrm{~km}$ away from it. The area is also connected through Highway NH-31A runs from Siliguri to Gangtok and the total distance from Siliguri to Pakyong is $120 \mathrm{~km}$. Though Sikkim back then does not have its own airport, so the nearest airport to it was at Bagdogra which was $16 \mathrm{~km}$ from Siliguri, and Sikkim is well linked through road as well as through regular helicopter service from Gangtok, but there is a huge rush on Bagdogra for visitors to Sikkim region during peak tourist season (March-July), every year, and thereby 
need of another airport as the public facility has been realised for smooth commutation, besides the development of such infrastructure would be helpful in post disaster response implementation.

The area of study is geotectonically very complex and is having intriguing tectonic units, which have strong bearing on Seismogenesis [4] [5]. The major tectonic features traversing the Sikkim Himalaya has the well defined Main Boundary Thrust (MBT), which is marked as the boundary between the Siwalik and Lesser Himalaya Domain (LHD), and the Main Central Thrust (MCT) to the north between LHD and Higher Himalayan Domain (HHD) take sinusoidal turn in the Sikkim Himalaya juxtaposes high grade gneisses of the Higher Himalayan Crystalline (HHC) and lower grade slates, phyllites and schists of the lesser Himalaya formations. The Main Frontal Thrust (MFT) separates Siwalik formation rock to the north and Gangetic plain to the south [3] [6]. The proposed Pakyong airport is located in the down slope to the East of the MCT and is bounded by lineaments (Kanchanjangha Lineament, Tista Lineament, Goalpara lineament, Gangtok Lineament) further to its east, which has history of generating micro to moderate earthquakes, including the 2011 Sikkim earthquake ( $\mathrm{Mw}$ 6.9) suggesting that the study area is tectonically active and is vulnerable where the Pakyong airport was proposed, such tectonic scenario demanded the detailed investigations of the site specific soil characteristics to understand the degree of its amplification during earthquake shaking and to estimate different sets of frequency for varying amount of amplification factor that can designate zones into various types of low, moderate and high risk categories by analyzing all three sets of parameters consisted of peak frequency, peak amplification and site vulnerability index.

The Major litho-units in the area are Phyllites, Schists with intercalations of Quartzite (Figure 2). The rock types mainly belong to Lesser Himalayas. The stratigraphy is complicated because of large scale faults and thrusts. The Lithostratigraphy has been divided into different cycles by Geological Survey of India [3].

Geotectonic settings of the study area had already been discussed in the report. The main litho units in and around Pakyong area that belongs to Gorubathan Formation of Daling Group (Proterozoic undifferentiated) and are represented by low grade metapelitic rocks such as phyllite and schist with thin intercalations of quartzites (Figure 2). The geological setting and stratigraphic position of the rock units is complex due to intense tectonics, polyphase deformation and metamorphism. The regional tectono-stratigraphic sequence of the rock types exposed in Sikkim is as follows [3] [7] [8].

It is also found that some of the places are associated with the rock, which is schistose and friable due to development of chlorite, mica and sericite.

\section{Data and Methodology}

In order to conduct a detailed site response study, the area is investigated by setting up of a grid pattern with station interval varying from $0.5 \mathrm{~km}$ to $1 \mathrm{~km}$ 


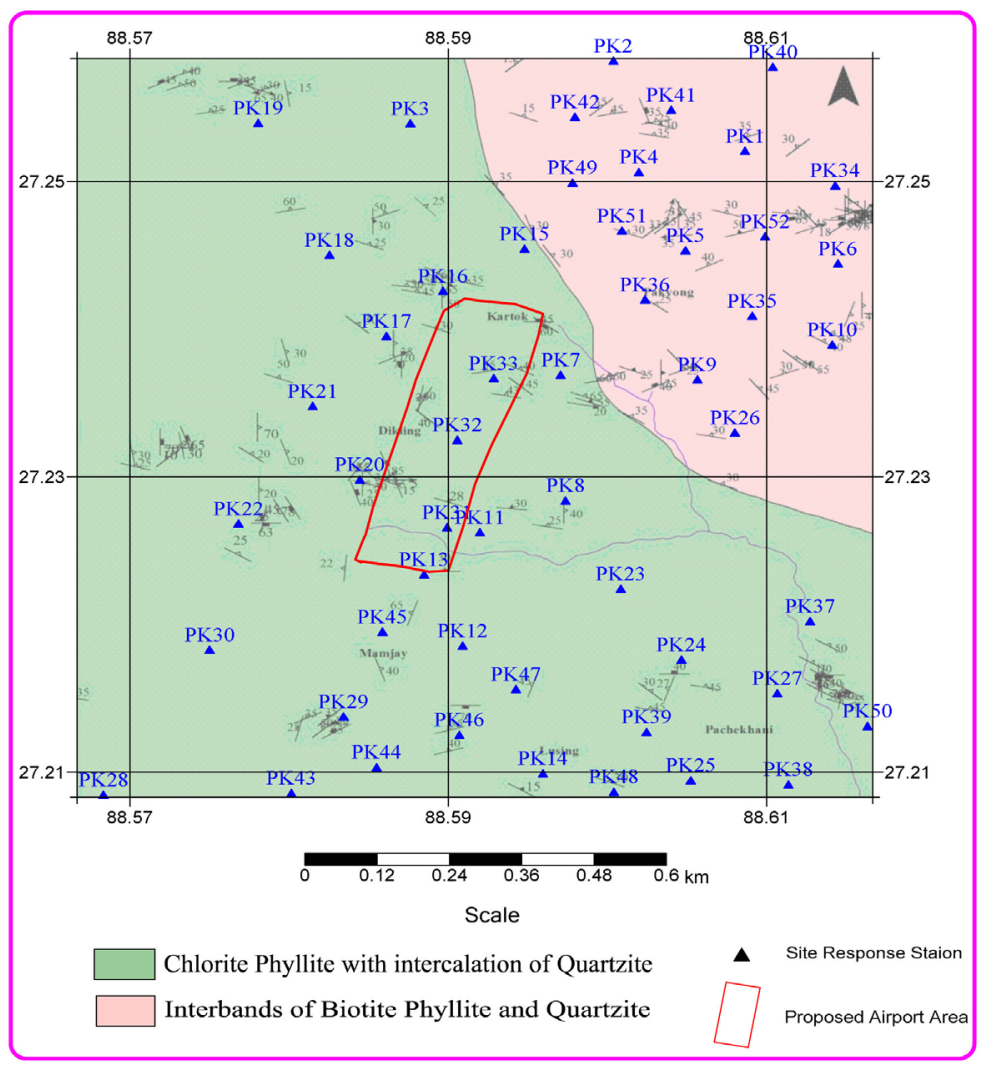

Figure 2. Geological map with site response station of proposed Pakyong airport, Sikkim (adapted from the report by [3]).

between neighbouring stations for the distribution of 52 stations for the ambient noise survey in the area (Figure 3; Table 1). Data were recorded based on the accessibility, availability of space and approach using high resolution seismograph of Nanometrics. In this study, ambient noise data was recorded for continuous 2 hours using short period seismograph of Nanometrics. Seismographs designed to be sensitive to high frequencies ranging from $1 \mathrm{~Hz}$ to $50 \mathrm{~Hz}$ are called short period seismographs. Data recorded is in the mini-SEED format which is then converted to SEISAN format and further to SAF format to be processed in Geopsy using Nakamura technique, which has wide-scale applicability in site-specific study elsewhere in India for different studies [2] [9]-[15]. It is worth to mention that the gap in between stations is mainly because of non-approachability along the steep slopes of hills and dense forest.

The site response results in terms of peak amplification, peak frequency and vulnerability index (Table 1), were thoroughly analyzed to arrive at a conclusion to understand which zones have what extent of vulnerability at sites.

\section{Site Response Study: Seismic Microzonation}

Site response study is one of the most important ingredients of Seismic Microzonation depending upon the local geology of an area, the degree of ground shaking gets modulated and changeable, which may further influence the damage to infrastructures. Unconsolidated sediments tend to amplify the ground 
Table 1. Site response station locations in and around Pakyong, Sikkim, Code: LHZ/NER/SSK/2013/035, FS: 2013-14.

\begin{tabular}{|c|c|c|c|c|c|c|c|}
\hline $\begin{array}{l}\text { Sl. } \\
\text { No. }\end{array}$ & $\begin{array}{l}\text { Stn. } \\
\text { No. }\end{array}$ & Location & Latitude & Longitude & $\begin{array}{c}\text { f0 } \\
\text { (Peak freq.) Hz }\end{array}$ & $\begin{array}{c}\text { A0 } \\
\text { (Peak ampl.) }\end{array}$ & $\begin{array}{l}\text { Vulnerability Index } \\
\qquad K_{g}=A_{0}^{2} / f_{0}\end{array}$ \\
\hline 1 & PK1 & Simsing & $27^{\circ} 15^{\prime} 07.2^{\prime \prime}$ & $88^{\circ} 36^{\prime} 31.1^{\prime \prime}$ & 0.71 & 5.72 & 46.1 \\
\hline 2 & PK2 & Namchepung & $27^{\circ} 15^{\prime} 29.2^{\prime \prime}$ & $88^{\circ} 36^{\prime} 1.3^{\prime \prime}$ & 5.87 & 2.59 & 1.1 \\
\hline 3 & PK3 & Namchepung & $27^{\circ} 15^{\prime} 13.9^{\prime \prime}$ & $88^{\circ} 35^{\prime} 15.4^{\prime \prime}$ & 0.88 & 4.16 & 19.7 \\
\hline 4 & PK4 & Basnettgoan & $27^{\circ} 15^{\prime} 02.1^{\prime \prime}$ & $88^{\circ} 36^{\prime} 07.1^{\prime \prime}$ & 3.48 & 2.40 & 1.7 \\
\hline 5 & PK5 & Samsing & $27^{\circ} 14^{\prime} 43^{\prime \prime}$ & $88^{\circ} 36^{\prime} 17.6^{\prime \prime}$ & 0.66 & 4.66 & 32.9 \\
\hline 6 & PK6 & Pakyong & $27^{\circ} 14^{\prime} 39.8^{\prime \prime}$ & $88^{\circ} 36^{\prime} 52.1^{\prime \prime}$ & 0.66 & 2.37 & 8.5 \\
\hline 7 & PK7 & Tsalumthang & $27^{\circ} 14^{\prime} 12.6^{\prime \prime}$ & $88^{\circ} 35^{\prime} 49.4^{\prime \prime}$ & 0.81 & 5.97 & 44.0 \\
\hline 8 & PK8 & Tsalumthang & $27^{\circ} 13^{\prime} 42.0^{\prime \prime}$ & $88^{\circ} 35^{\prime} 50.5^{\prime \prime}$ & 6.63 & 3.10 & 1.4 \\
\hline 9 & PK9 & Dugalakha & $27^{\circ} 14^{\prime} 11.5^{\prime \prime}$ & $88^{\circ} 36^{\prime} 20.3^{\prime \prime}$ & 6.58 & 2.54 & 1.0 \\
\hline 10 & PK10 & Dugalakha & $27^{\circ} 14^{\prime} 19.9^{\prime \prime}$ & $88^{\circ} 36^{\prime} 50.8^{\prime \prime}$ & 0.73 & 7.04 & 67.9 \\
\hline 11 & PK11 & Dikling & $27^{\circ} 13^{\prime} 34.3^{\prime \prime}$ & $88^{\circ} 35^{\prime} 31.1^{\prime \prime}$ & 0.84 & 3.37 & 13.5 \\
\hline 12 & PK12 & Mamjay & $27^{\circ} 13^{\prime} 06.6^{\prime \prime}$ & $88^{\circ} 35^{\prime} 27.2^{\prime \prime}$ & 0.99 & 2.91 & 8.6 \\
\hline 13 & PK13 & Gumpa & $27^{\circ} 13^{\prime} 24.0^{\prime \prime}$ & $88^{\circ} 35^{\prime} 18.5^{\prime \prime}$ & 0.67 & 3.37 & 17.0 \\
\hline 14 & PK14 & Lusing & $27^{\circ} 12^{\prime} 35.5^{\prime \prime}$ & $88^{\circ} 35^{\prime} 45.4^{\prime \prime}$ & 0.83 & 3.20 & 12.3 \\
\hline 15 & PK15 & Namchepung & $27^{\circ} 14^{\prime} 43.4^{\prime \prime}$ & $88^{\circ} 35^{\prime} 41.2^{\prime \prime}$ & 1.07 & 2.34 & 5.1 \\
\hline 16 & PK16 & North Kartoke & $27^{\circ} 14^{\prime} 33.1^{\prime \prime}$ & $88^{\circ} 35^{\prime} 22.8^{\prime \prime}$ & 0.66 & 3.46 & 18.1 \\
\hline 17 & PK17 & North Kartoke & $27^{\circ} 14^{\prime} 22.2^{\prime \prime}$ & $88^{\circ} 35^{\prime} 10.0^{\prime \prime}$ & 0.63 & 11.79 & 220.6 \\
\hline 18 & PK18 & Raigoan & $27^{\circ} 14^{\prime} 41.9^{\prime \prime}$ & $88^{\circ} 34^{\prime} 57.1^{\prime \prime}$ & 10.61 & 5.0 & 2.4 \\
\hline 19 & PK19 & Pirikalakha & $27^{\circ} 15^{\prime} 14.0^{\prime \prime}$ & $88^{\circ} 34^{\prime} 41.0^{\prime \prime}$ & 3.99 & 2.76 & 1.9 \\
\hline 20 & PK20 & Dikling & $27^{\circ} 13^{\prime} 47.1^{\prime \prime}$ & $88^{\circ} 35^{\prime} 04.0^{\prime \prime}$ & 10.80 & 1.47 & 0.2 \\
\hline 21 & PK21 & Naya Basti & $27^{\circ} 14^{\prime} 5.0^{\prime \prime}$ & $88^{\circ} 34^{\prime} 53.3^{\prime \prime}$ & 0.72 & 5.76 & 46.1 \\
\hline 22 & PK22 & Damlakha & $27^{\circ} 13^{\prime} 36.4^{\prime \prime}$ & $88^{\circ} 34^{\prime} 36.5^{\prime \prime}$ & 8.20 & 2.62 & 0.8 \\
\hline 23 & PK23 & Satmali & $27^{\circ} 13^{\prime} 20.5^{\prime \prime}$ & $88^{\circ} 36^{\prime} 03.0^{\prime \prime}$ & 0.67 & 3.92 & 22.9 \\
\hline 24 & PK24 & Dikling/Pachey khani & $27^{\circ} 13^{\prime} 03.2^{\prime \prime}$ & $88^{\circ} 36^{\prime} 16.7^{\prime \prime}$ & 0.60 & 4.80 & 38.4 \\
\hline 25 & PK25 & Pacheykhani & $27^{\circ} 12^{\prime} 33.8^{\prime \prime}$ & $88^{\circ} 36^{\prime} 18.8^{\prime \prime}$ & 0.65 & 2.66 & 10.9 \\
\hline 26 & PK026 & Dugalakha & $27^{\circ} 13^{\prime} 58.5^{\prime \prime}$ & $88^{\circ} 36^{\prime} 28.8^{\prime \prime}$ & 0.66 & & \\
\hline 27 & PK27 & Pacheykhani & $27^{\circ} 12^{\prime} 55^{\prime \prime}$ & $88^{\circ} 36^{\prime} 38.4^{\prime \prime}$ & 11.21 & 2.72 & 0.7 \\
\hline 28 & PK28 & Pachak & $27^{\circ} 12^{\prime} 30.3^{\prime \prime}$ & $88^{\circ} 34^{\prime} 06.0^{\prime \prime}$ & 3.20 & 1.68 & 0.9 \\
\hline 29 & PK29 & Pachak & $27^{\circ} 12^{\prime} 49.3^{\prime \prime}$ & $88^{\circ} 35^{\prime} 00.3^{\prime \prime}$ & 0.67 & 5.50 & 45.1 \\
\hline 30 & PK30 & Pachem & $27^{\circ} 13^{\prime} 05.6^{\prime \prime}$ & $88^{\circ} 34^{\prime} 30^{\prime \prime}$ & 12.11 & 2.61 & 0.5 \\
\hline 31 & PK31 & Airport & $27^{\circ} 13^{\prime} 35.5^{\prime \prime}$ & $88^{\circ} 35^{\prime} 23.7^{\prime \prime}$ & 1.93 & 4.06 & 8.5 \\
\hline 32 & PK32 & Airport & $27^{\circ} 13^{\prime} 56.8^{\prime \prime}$ & $88^{\circ} 35^{\prime} 26.0^{\prime \prime}$ & 0.73 & 9.87 & 133.4 \\
\hline 33 & PK33 & Airport & $27^{\circ} 14^{\prime} 11.8^{\prime \prime}$ & $88^{\circ} 35^{\prime} 34.3^{\prime \prime}$ & 0.70 & 6.44 & 59.2 \\
\hline 34 & PK34 & Assam Lingzey road & $27^{\circ} 14^{\prime} 58.8^{\prime \prime}$ & $88^{\circ} 36^{\prime} 51.5^{\prime \prime}$ & 9.00 & 3.27 & 1.2 \\
\hline 35 & PK35 & Pachey & $27^{\circ} 14^{\prime} 27.0^{\prime \prime}$ & $88^{\circ} 36^{\prime} 32.7^{\prime \prime}$ & 11.86 & 2.07 & 0.4 \\
\hline
\end{tabular}




\section{Continued}

\begin{tabular}{|c|c|c|c|c|c|c|c|}
\hline 36 & PK36 & Pakyong & $27^{\circ} 14^{\prime} 31.0^{\prime \prime}$ & $88^{\circ} 36^{\prime} 08.5^{\prime \prime}$ & 11.61 & 2.68 & 0.6 \\
\hline 37 & PK37 & Pacheykhani & $27^{\circ} 13^{\prime} 12.6^{\prime \prime}$ & $88^{\circ} 36^{\prime} 45.8^{\prime \prime}$ & 0.69 & 3.37 & 16.5 \\
\hline 38 & PK38 & Tarabari (Pacheykhani) & $27^{\circ} 12^{\prime} 32.8^{\prime \prime}$ & $88^{\circ} 36^{\prime} 40.9^{\prime \prime}$ & 1.46 & 2.05 & 2.9 \\
\hline 39 & PK39 & Pacheykhani & $27^{\circ} 12^{\prime} 45.6^{\prime \prime}$ & $88^{\circ} 36^{\prime} 08.8^{\prime \prime}$ & 1.80 & 2.32 & 3.0 \\
\hline 40 & PK40 & Samsing & $27^{\circ} 15^{\prime} 27.7^{\prime \prime}$ & $88^{\circ} 36^{\prime} 37.4^{\prime \prime}$ & 0.73 & 2.97 & 12.1 \\
\hline 41 & PK41 & Namchepung & $27^{\circ} 15^{\prime} 17.2^{\prime \prime}$ & $88^{\circ} 36^{\prime} 14.4^{\prime \prime}$ & 9.53 & 2.07 & 0.4 \\
\hline 42 & PK42 & Namchepung & $27^{\circ} 15^{\prime} 15.5^{\prime \prime}$ & $88^{\circ} 35^{\prime} 52.6^{\prime \prime}$ & 0.66 & 1.77 & 4.7 \\
\hline 43 & PK43 & Padamchey & $27^{\circ} 12^{\prime} 30.7^{\prime \prime}$ & $88^{\circ} 34^{\prime} 48.5^{\prime \prime}$ & 0.65 & 3.47 & 18.5 \\
\hline 44 & PK44 & Padamchey & $27^{\circ} 12^{\prime} 37.0^{\prime \prime}$ & $88^{\circ} 35^{\prime} 07.8^{\prime \prime}$ & 1.98 & 3.01 & 4.6 \\
\hline 45 & PK45 & Mamjay & $27^{\circ} 13^{\prime} 10.0^{\prime \prime}$ & $88^{\circ} 35^{\prime} 09.1^{\prime \prime}$ & 0.68 & 4.47 & 29.4 \\
\hline 46 & PK46 & Lusing & $27^{\circ} 12^{\prime} 44.9^{\prime \prime}$ & $88^{\circ} 35^{\prime} 26.5^{\prime \prime}$ & 0.96 & 3.84 & 15.4 \\
\hline 47 & PK47 & Krisnotar (Upper Loosing) & $27^{\circ} 12^{\prime} 56.0^{\prime \prime}$ & $88^{\circ} 35^{\prime} 39.3^{\prime \prime}$ & 0.62 & 8.92 & 128.3 \\
\hline 48 & PK48 & Loosing & $27^{\circ} 12^{\prime} 31.0^{\prime \prime}$ & $88^{\circ} 36^{\prime} 01.4^{\prime \prime}$ & 0.63 & 10.42 & 17.2 \\
\hline 49 & PK49 & Namchepung (Basnettgaon) & $27^{\circ} 14^{\prime} 59.5^{\prime \prime}$ & $88^{\circ} 35^{\prime} 52.1^{\prime \prime}$ & 0.72 & 8.22 & 93.8 \\
\hline 50 & PK50 & Taaza & $27^{\circ} 12^{\prime} 47.0^{\prime \prime}$ & $88^{\circ} 36^{\prime} 58.8^{\prime \prime}$ & 0.77 & 2.16 & 6.1 \\
\hline 51 & PK51 & Naibu & $27^{\circ} 14^{\prime} 47.6^{\prime \prime}$ & $88^{\circ} 36^{\prime} 03.2^{\prime \prime}$ & 0.65 & 8.88 & 121.3 \\
\hline 52 & PK52 & Samsing & $27^{\circ} 14^{\prime} 46.4^{\prime \prime}$ & $88^{\circ} 36^{\prime} 35.6^{\prime \prime}$ & 0.60 & 4.29 & 30.7 \\
\hline
\end{tabular}

Location Map of site response stations of proposed Pakyong airport, Sikkim

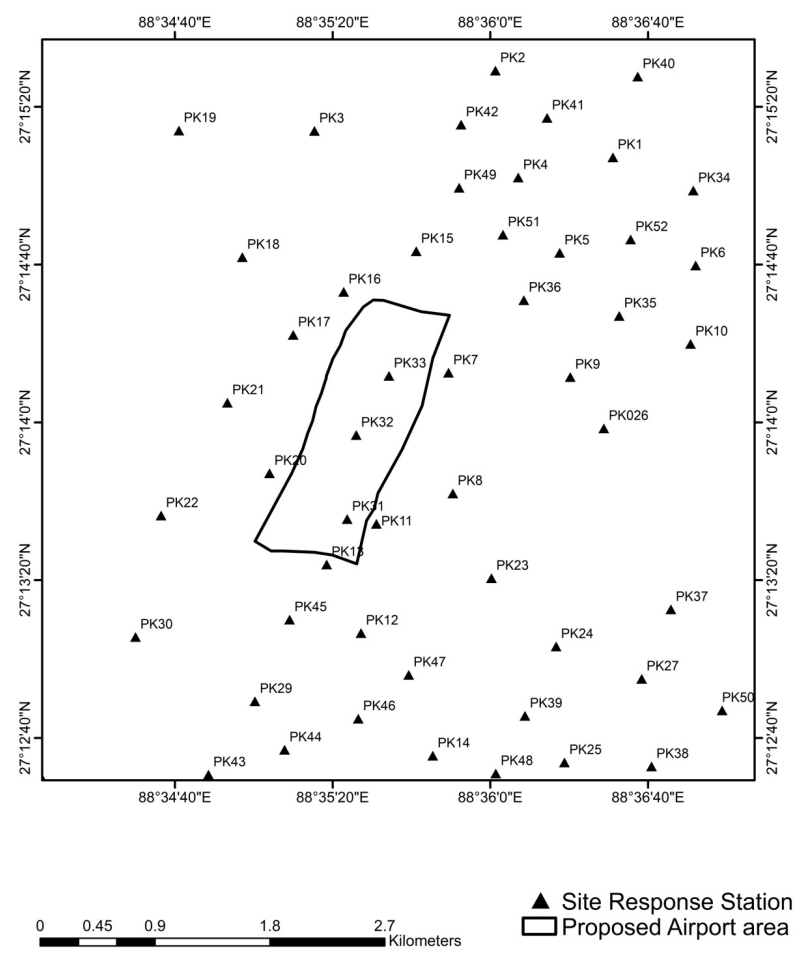

Figure 3. Location map of site response stations of proposed Pakyong airport, Sikkim. 
motion during earthquake. The amplitude of earthquake ground motion can be increased or decreased by the properties and configuration of the near surface material through which seismic wave propagate. As a seismic wave pass through the media of increasing impedance the amplitude of the seismic wave decreases. Increase in amplitude is greater on soft soils than on hard rocks. At higher frequencies the impact of absorption can be very severe while at low frequencies gets lesser.

Source characterization is an essential parameter to adjudge the nature and extent of excitation of different soil layers for which source can be located at near or shallow/surface or it can be located at a distance inside the sediments or it can be at deeper location inside the bedrock. All these features can be distinctly distinguished by analyzing peaks in $H / V$ ratio. Thus, source characterization can be made on various characteristics, which have been thoroughly studied and ascertained following facts. It is observed that a single peak is observed in $H / V$ curve in the case when the source is near and on surface, on the other hand double peak in $H / V$ graph may happen due to the source at a distance and located inside the sedimentary layer. Most importantly, $H / V$ ratio exhibits peak at the fundamental and harmonic resonance frequencies when sources are deep, located inside the bedrock, while surface sources are the major controlling factors for $H / V$ peaks.

We used Nakamura technique that uses the $H / V$ ratio, which is the ratio between the Fourier spectra of the horizontal and vertical components of ambient noise. It is also defined as the ratio of horizontal-to vertical component of ground motion. The advantage of this technique is that it is simple to apply, and does not require a reference station. $H / V$ is basically related to the ellipticity of Rayleigh waves in vertical component. This ellipticity is frequency dependent and exhibits a sharp peak around the fundamental frequency for sites displaying a high enough impedance contrast between the surface and deep materials. On soft soils the ratio exhibits a clear peak that is well correlated with the fundamental resonant frequency. Nakamura noted that in the basement to surface layer, frequency dependent horizontal transfer function $T B_{S}(f)$ that $H_{S}(f)$ is readily affected by locally generated social noise, which mainly consists of Rayleigh waves. Nakamura also noted that the vertical spectrum at the surface layer $V_{S}(f)$ should include the local Rayleigh wave contribution, but the basement vertical spectrum $V_{B}(f)$ is devoid of Rayleigh wave (Figure 4). The surface layer does not amplify the vertical ground motion, the effect of the local Rayleigh waves on the incident microtremor motion within the surface layer that can be presented as the ratio of vertical spectrum at the surface layer $\left[V_{s}(f)\right]$ to the basement vertical spectrum $\left[V_{B}(f)\right]$, which can be mathematically expressed as:

$$
E_{R}=V_{s} / V_{B}
$$

$H / V$ spectral ratio studies interpret the Nakamura's technique in relation to the ellipticity ratio of Rayleigh waves for which high enough impedance contrast exhibits pronounced peak close to the fundamental S-wave resonance frequency. Nakamura technique, we used in this study is based on the assumptions such as: 


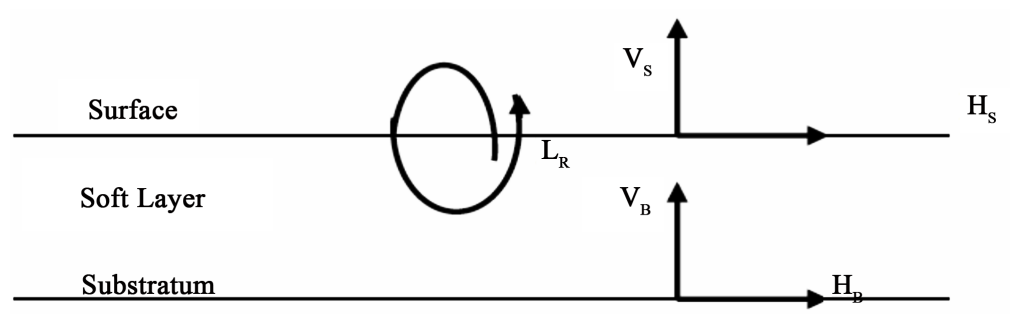

Figure 4. A schematic diagram for deriving $H / V$ ratio.

Microtremors are composed mainly of Rayleigh waves, propagating in the soft surface layers overlying the half space;

The microtremors are originated by local surface source (traffic and industrial noise etc.) and they have no contribution from deep sources;

The amplification of the vertical component is exclusively associated with the depth dependence of the surface (Rayleigh) wave motion.

The transfer functions of surface layers can be given by the ratio

Transfer Function of Surface Layer:

$$
S=H_{s} / H_{B}
$$

However, considering the great contribution of Rayleigh wave propagation for the ambient noise, it will be necessary to convert the ratio $H_{S} / H_{B}$, in order to estimate a transfer function for microtremor measurements (assuming that the vertical tremor is not amplified by the surface layers). The ratio $E_{R}$ defined below should represent the effect of the Rayleigh wave on the vertical motion.

Rayleigh Surface Wave Energy ratio can be expressed as given in Equation (1).

Assuming that the effect of the Rayleigh wave is equal for vertical and horizontal components, using Equation (1) \& Equation (2), we can get a corrected modified spectral ratio $\left(S_{M}\right)$ as:

$$
S_{M}=S / E_{R}
$$

Computing values of " $S$ " and " $E_{R}$ " in Equation (3), we can get:

$$
\begin{gathered}
S_{M}=\left(H_{S} / H_{B}\right) /\left(V_{S} / V_{B}\right) \\
S_{M}=H_{S} / V_{S} \times H_{B} / V_{B}
\end{gathered}
$$

As a final condition it is assumed that for all frequencies of interest

$$
H_{B} / V_{B}=1 \text { or } V_{B} / H_{B}=1
$$

Thus, an estimate of the transfer function is given by the spectral ratio between the horizontal and the vertical components of the motion at the surface

$$
S_{M}=H_{s} / V_{s}
$$

It is therefore, the vertical component of microtremors on the surface retains the characteristics of horizontal component of hard rock. The main objective of deploying Nakamura's method in this study is to estimate maximum site amplification and corresponding predominant frequency of ground for site response study of the Pakyong airport site. The estimates of $H / V$ at every station of the site are shown in Figures 5(a)-(f). 

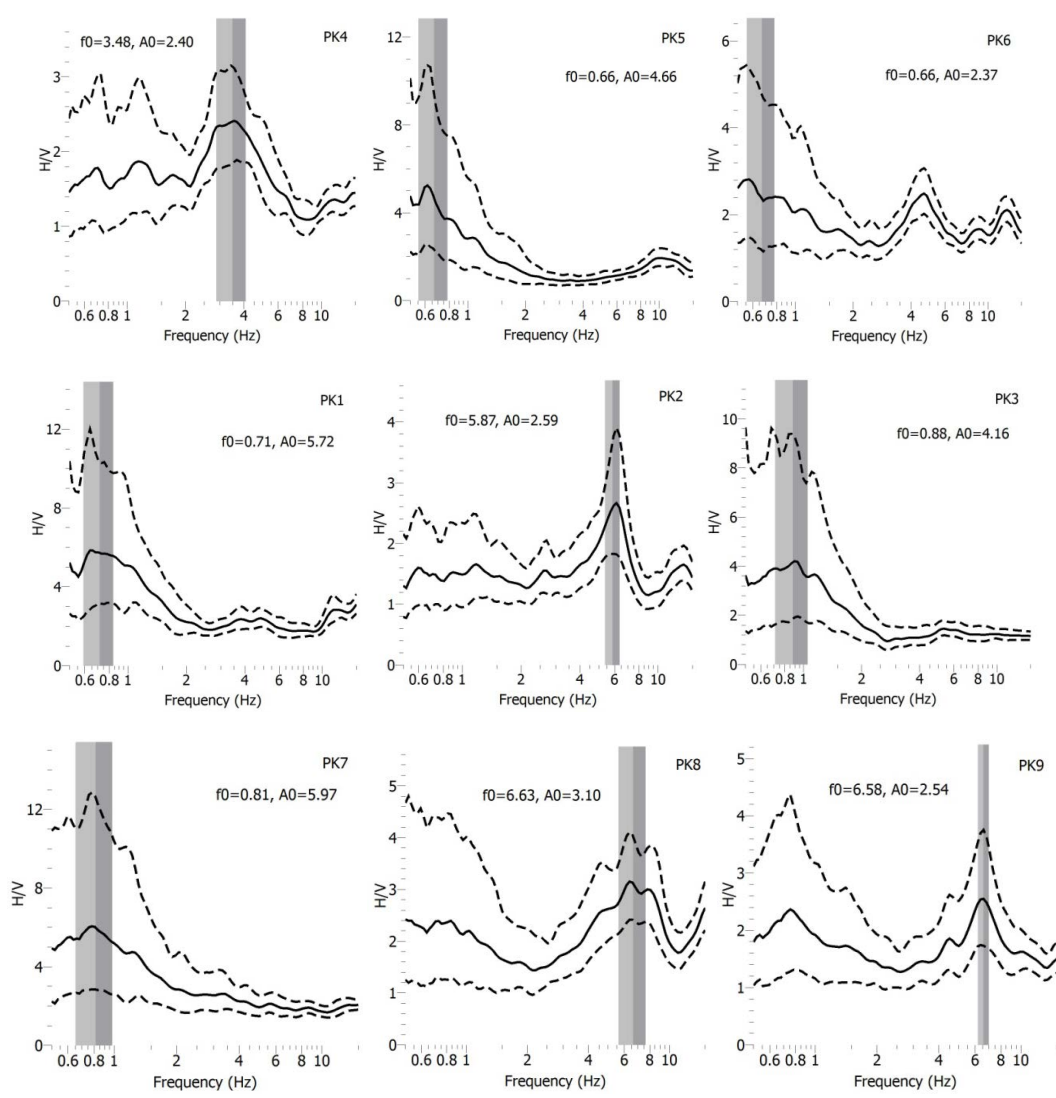

(a)
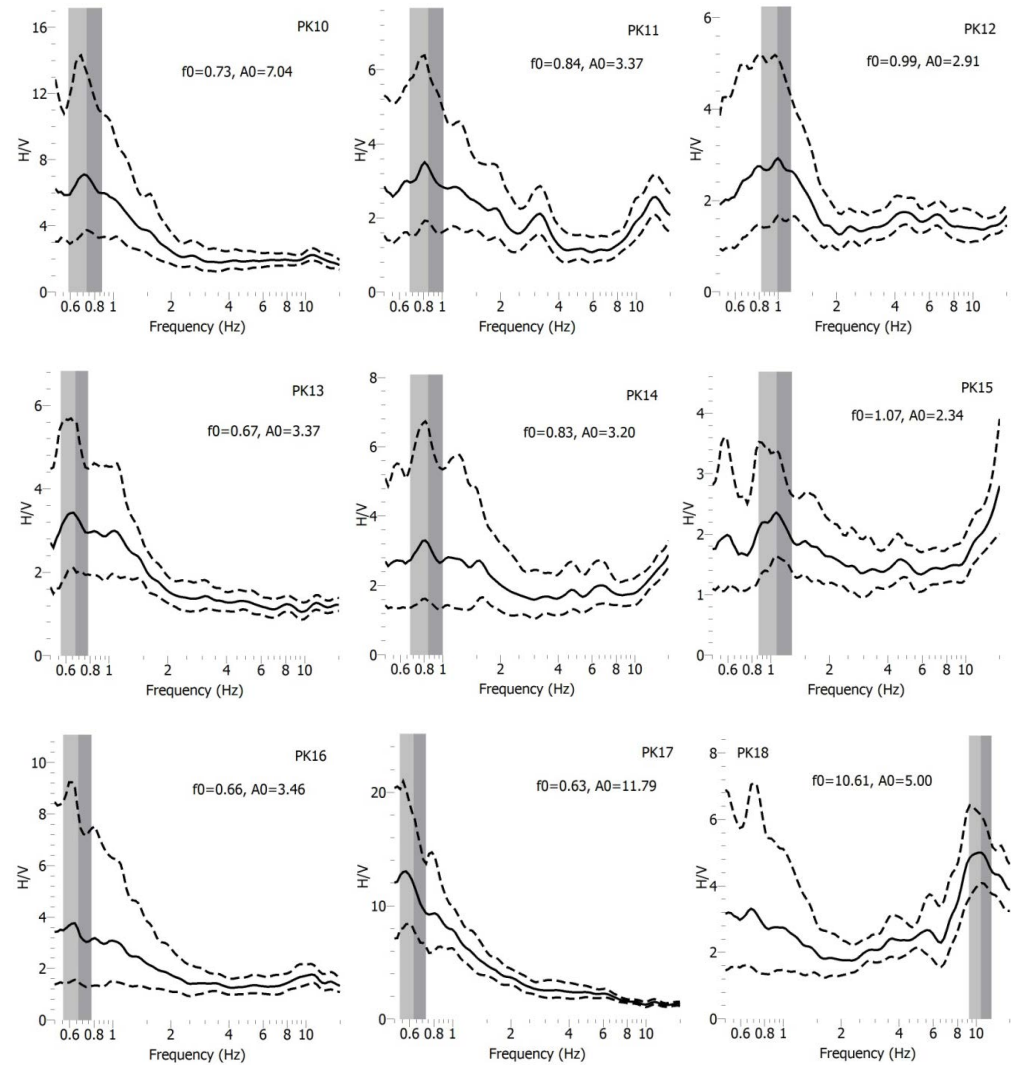

(b) 

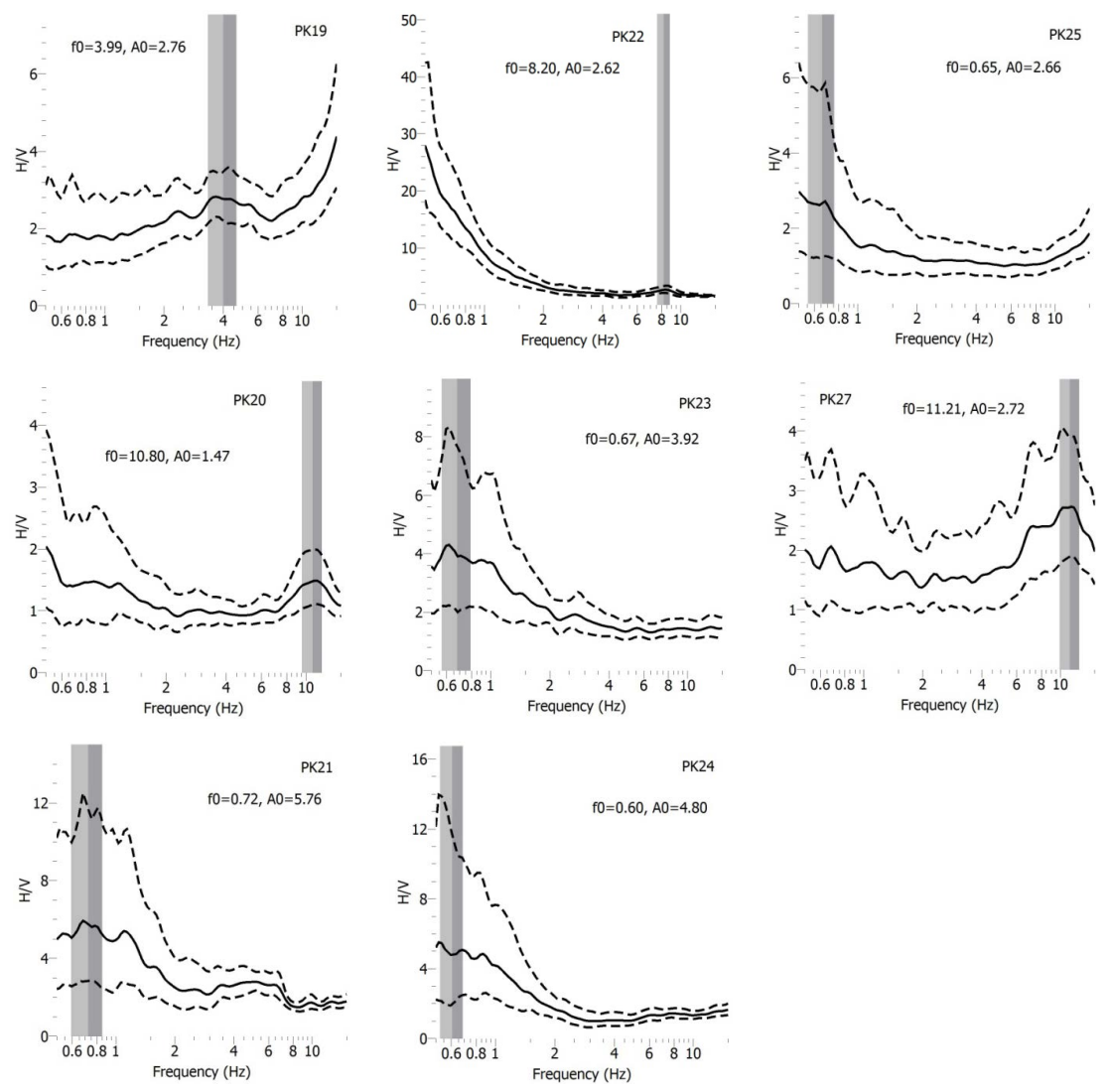

(c)
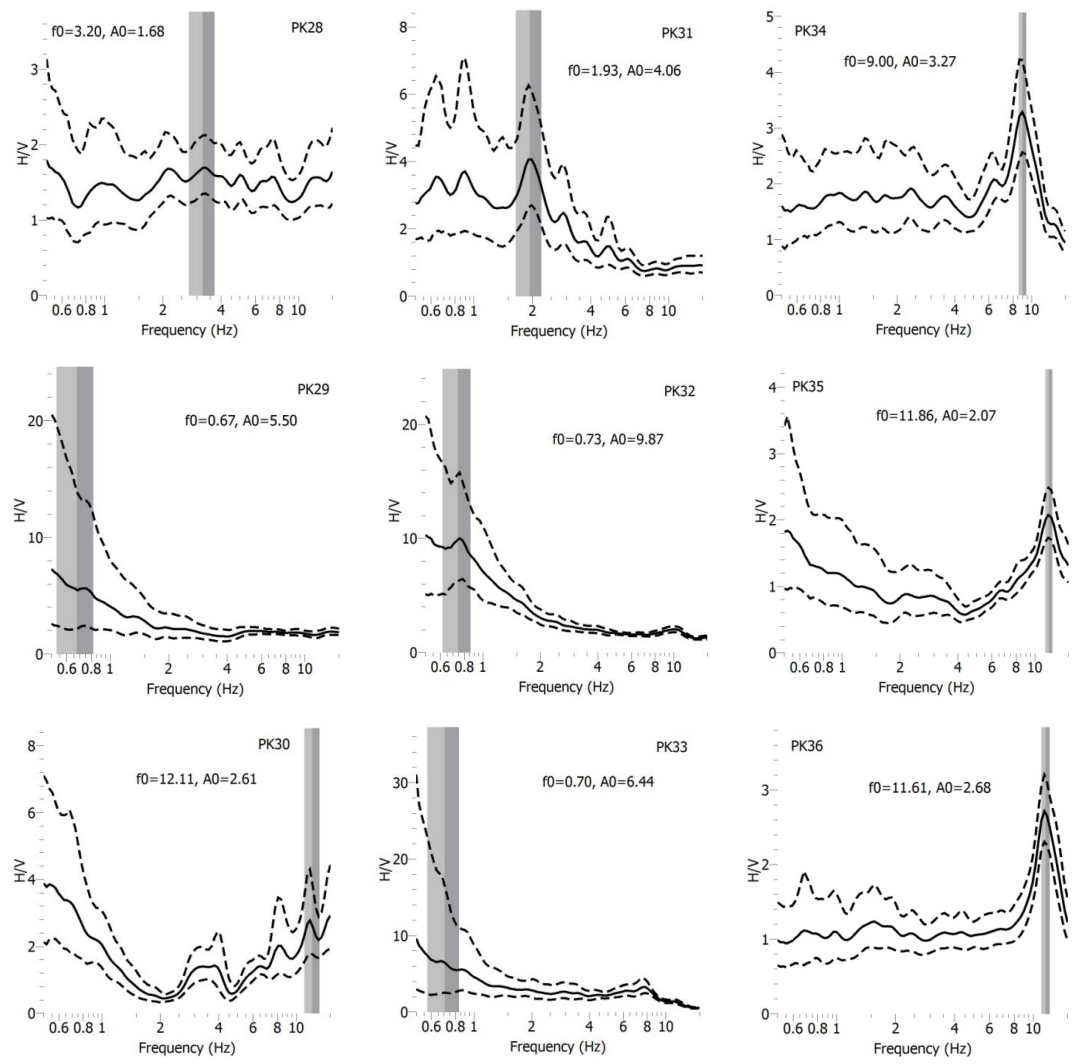

(d) 

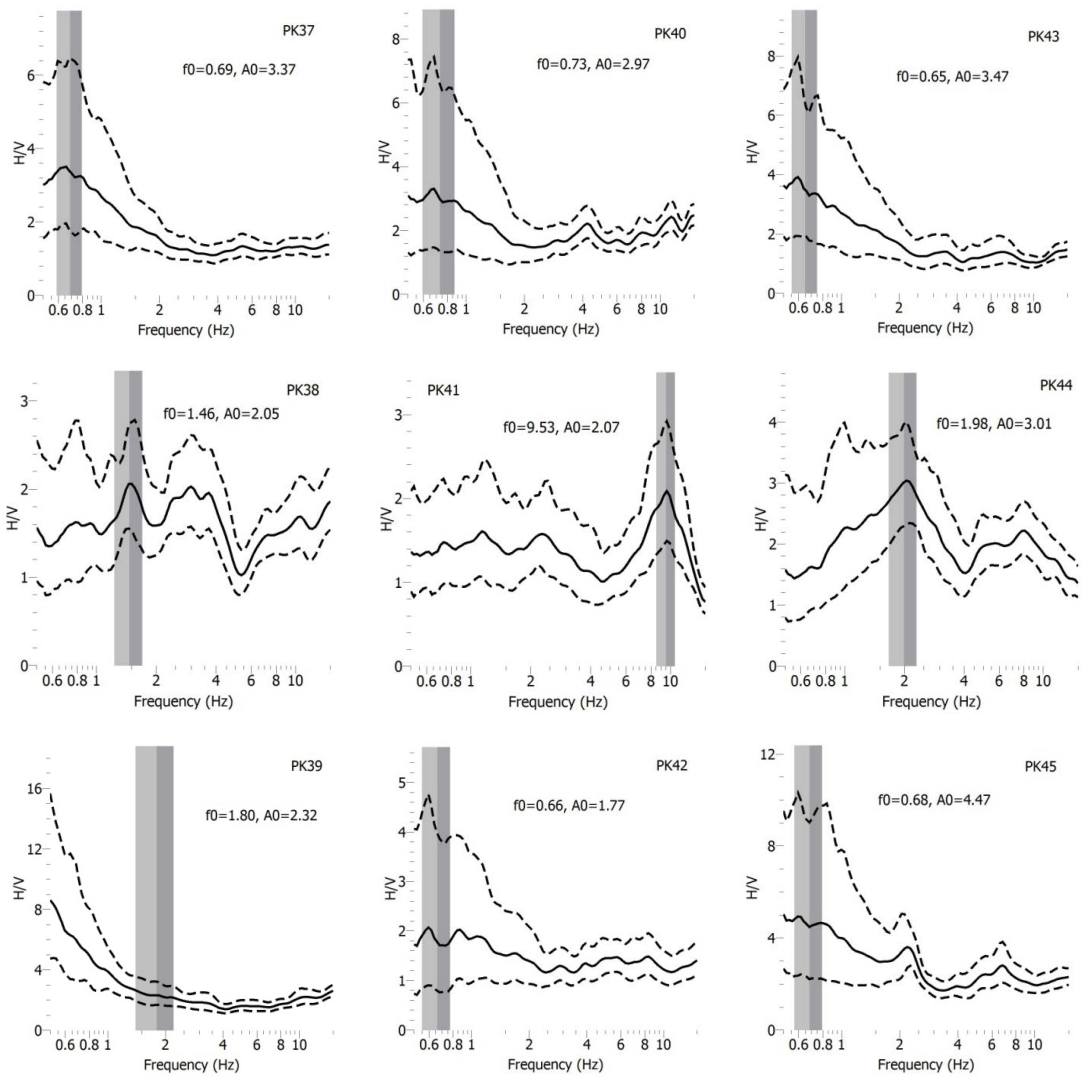

(e)
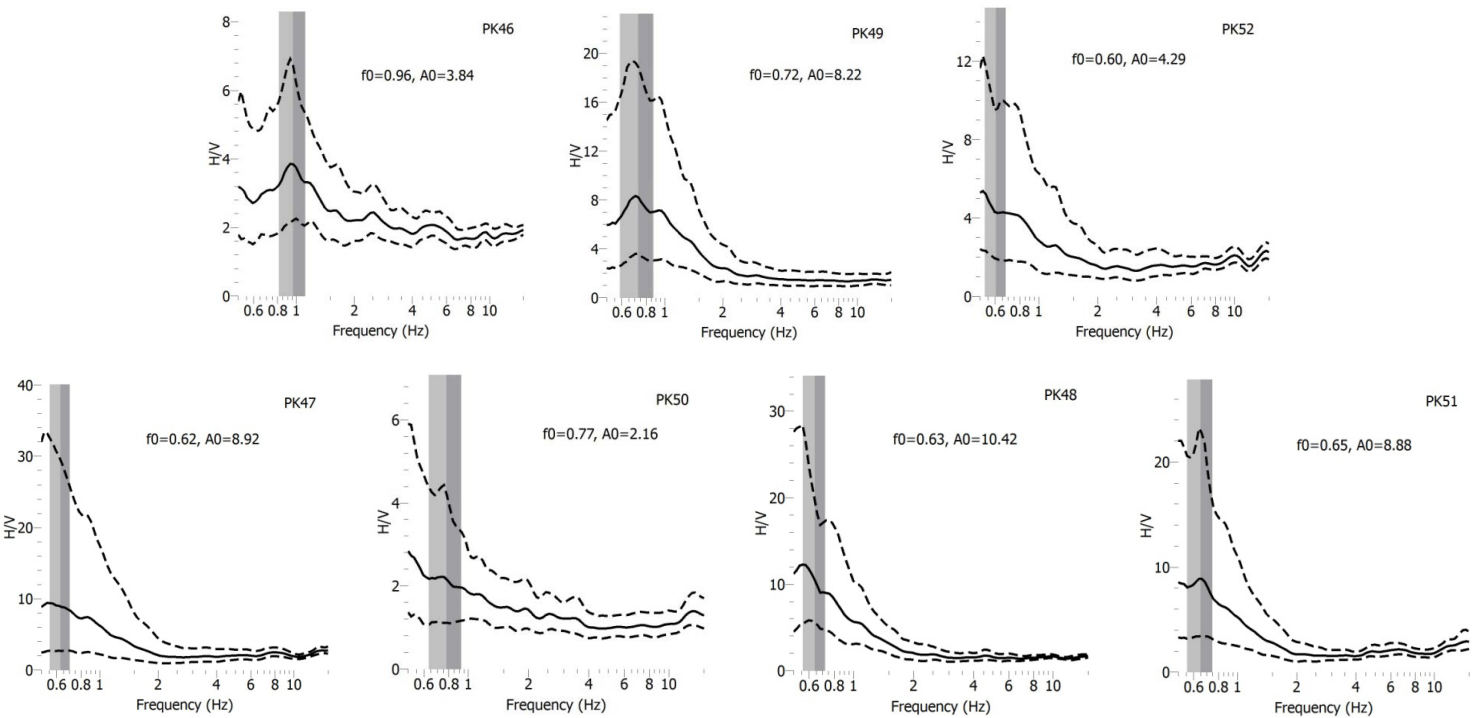

(f)

Figure 5. (a) $H / V$ spectrum of site response stations (PK1 to PK9) in and around Pakyong site, Sikkim. The thick curve shows the average of relative spectra and the upper and lower dotted line denote positive and negative standard deviation, respectively; (b) $H / V$ spectrum of site response stations (PK10 to PK18) in and around Pakyong site, Sikkim. Other notations are same as that of Figure 5(a); (c) H/ $V$ spectrum of site response stations (PK19 to PK25 and PK27) in and around Pakyong site, Sikkim. Other notations are same as that of Figure 5(a); (d) $H / V$ spectrum of site response stations (PK28 to PK 36) in and around Pakyong site, Sikkim. Other notations are same as that of Figure 5(a); (e) H/ $V$ spectrum of site response stations (PK37 to PK45) in and around Pakyong site, Sikkim. Other notations are same as that of Figure 5(a); (f) $H / V$ spectrum of site response stations (PK46 to PK52) in and around Pakyong site, Sikkim. Other notations are same as that of Figure 5(a). 
It is now understood that the amplitude of earthquake ground motion is affected by the properties and configuration of the near surface material through which seismic waves propagate. Amplitude of the maximum amplification is related mainly to the impedance contrast between the surface and the underlying bedrock, to the material damping in sediments and to the characteristics of the incident wave field (types of wave, incidence angle, near field or far field etc). The amplification $\left(A_{o}\right)$ at fundamental frequency $(F)$ is given by

$$
A_{o}=1 /\left(1 / C+0.5 \pi \zeta_{1}\right) \text {, }
$$

where, $C=\rho_{2} V_{2} / \rho_{1} V_{1}$ is the impedance contrast and $\zeta_{1}$ is the material damping of the sediments. In case of very small damping $\left(\zeta_{1}=0\right)$, the maximum amplification is simply double the impedance contrast and in case of small damping the maximum amplification is simply the impedance contrast.

Amplification of the ground occurs in the following field conditions:

1) Large amplification has been observed over loose, unconsolidated sediments.

2) Amplification is larger at mountain tops because of larger horizontal component of $S$ wave than that of vertical component of $P$ wave.

3) Earthquake damage is large over soft sediments than the hard rock because of trapping of seismic waves by soft sediments due to the impedance contrast between soft sediments and underlying bedrock.

4) Nonlinear behavior of soft soils during strong earthquakes is characterized by decreased amplification due to decrease in shear wave velocity and increase in material damping.

5) The amplification of higher peaks decreases with increasing frequency. The higher amplification of the soils will occur at the lowest natural frequency or its fundamental frequency. The period of variation corresponding to the fundamental frequency is called the characteristic site period.

$$
\begin{array}{ll}
\varpi=\frac{\pi V_{s}}{2 H} & \varpi_{0}=\text { fundamental frequencty } \\
V_{s}=\text { Shear wave velocity } \\
H=\text { Soil thickness } \\
T_{s}=\frac{2 \pi}{\varpi_{0}}=\frac{4 H}{V_{s}} & T_{s}=\text { Characteristic site }
\end{array}
$$

Based on above formulations we estimated Amplification factors for all stations (Figure 6) with corresponding Peak frequencies (Figure 7).

\section{Site vulnerability Index $\left(K_{g}\right)$}

Site Vulnerability $\left(K_{g}\right)$ is regarded as the most important parameter to estimate the degree of damage to the study area, because of its direct bearing on ground motion. $K_{g}$ values have been proposed by [16] for accurate estimates of earthquake damage to surface and structures. Vulnerability index, $K_{g}$, derived from resonant frequencies, $f_{0}$ and peak amplification factor, $A_{0}[17]$

$$
K_{g}=A_{0}^{2} / f_{0}
$$




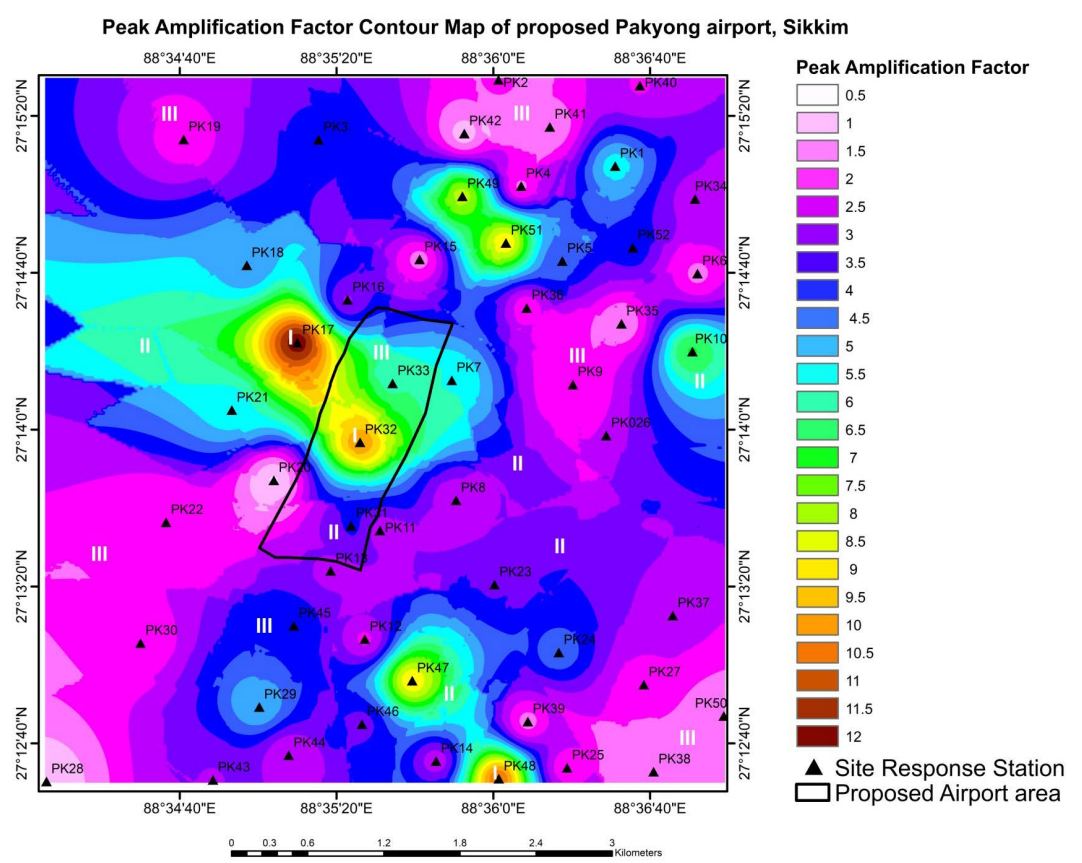

Figure 6. Distribution of Peak amplification factor as shown in the color scale in and around Pakyong site, Sikkim, India. The Black rectangle shows the boundary of the Pakyong airport site.

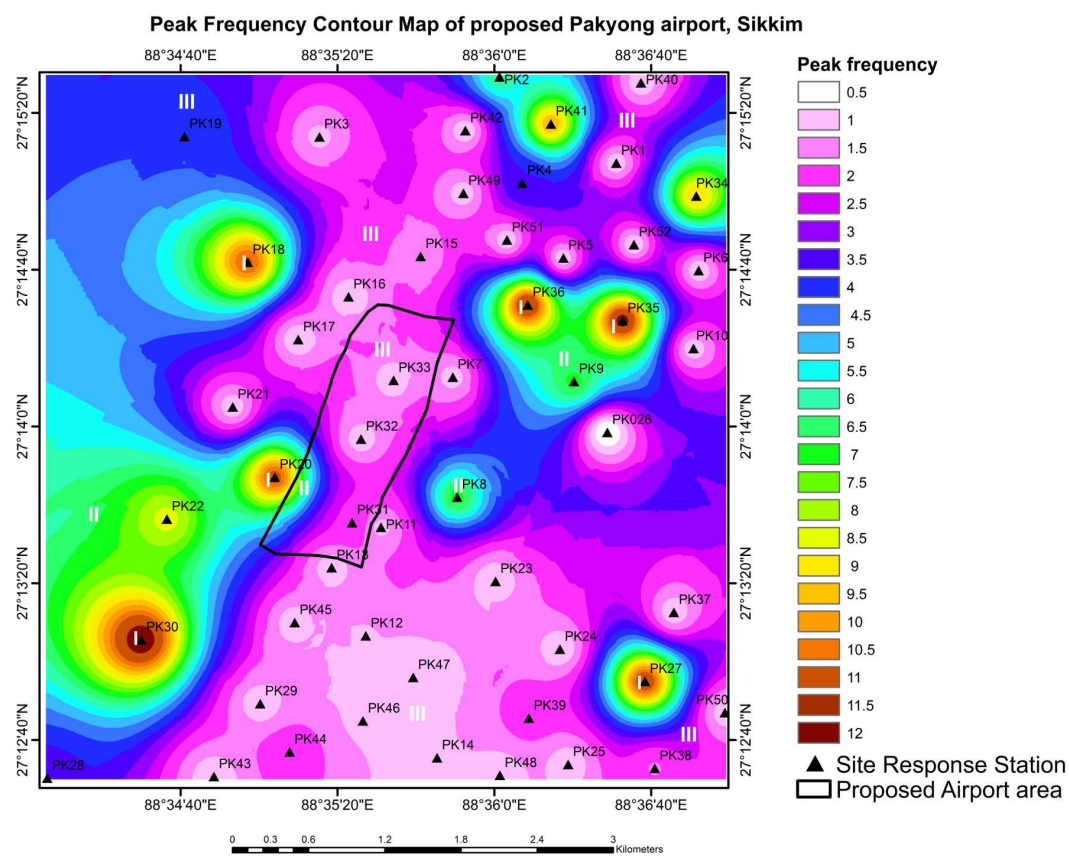

Figure 7. Distribution of Peak frequency in and around Pakyong site, Sikkim, India. Other notations have same meaning as that of Figure 6.

" $K_{g}^{\prime}$ ' is a value corresponding to the site and can be considered as a vulnerability index of the site, which might be useful to identify weaker and stronger sites of the ground. Figure 8 shows vulnerability for the sites of Pakyong area. After estimating the resonant frequencies, $f_{0}$ and peak amplification factor, $A_{o}$ 


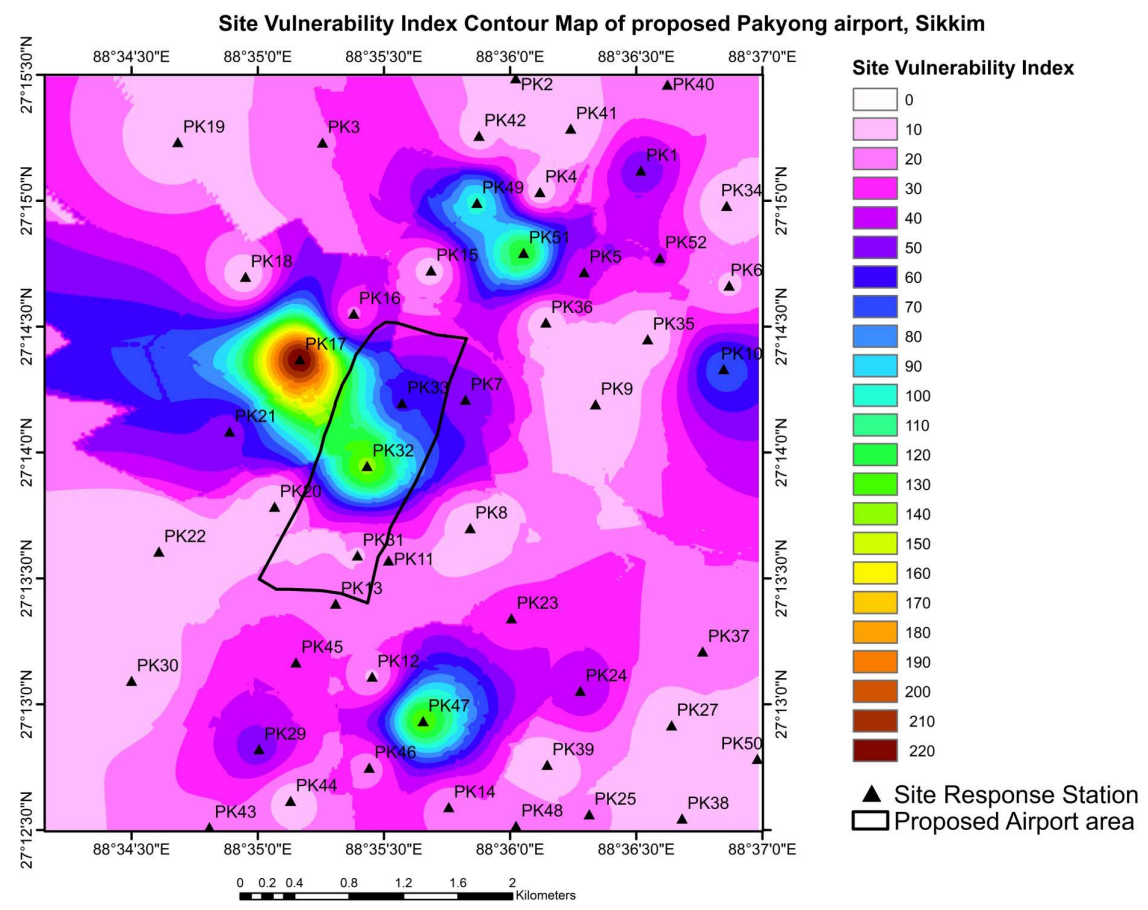

Figure 8. Distribution of Site Vulnerability Index in and around Pakyong airport site, Sikkim, India. Other notations have same meaning as that of Figure 6.

[17], $K_{g}$ values have been estimated for respective sites in order to make division into discrete zones of weak surface covers with respect to observation from $\mathrm{Na}$ kamura's technique.

\section{Results and Discussion}

The site specific soil characteristics to understand the degree of its amplification during earthquake shaking and to estimate different sets of frequency for varying amount of amplification factor can help designate zones into various types of low, moderate/intermediate, and high risk categories by analyzing all three sets of parameters consisted of peak frequency, peak amplification and site vulnerability index are as shown in Table 2.

As mentioned above, we obtained $H / V$ spectrum of the site response for all 52 stations of the study area [Figures 5(a)-(f)], Peak Amplification factor Map (Figure 6), Peak Frequency Map (Figure 7), and Site Vulnerability Index (Figure 8) for the study area, which shed an important light on distribution of all these three parameters in different zones (Zone I, Zone II, Zone III) of varying vulnerability (Table 2). It is found that the $H / V$ spectrum of site response for stations (PK 13, PK 20, PK 31, PK 32, PK 33) falling in the Pakyong airport area as shown in Figures 5(a)-(f). Detailed analysis of Figures 5(a)-(f) revealed that a single peak is observed in $H / V$ curve in the case when the source is near the surface. We also found double peak in $H / V$ graph, representing the source at a distance and located inside the sedimentary layer. It is worth to mention that peak of $H / V$ ratio at the fundamental and harmonic resonance frequencies, 
Table 2. Distribution of 3-parameters: peak frequency, peak amplification factor, and site vulnerability index.

\begin{tabular}{cccc}
\hline Parameters & Zone-I & Zone-II & Zone-III \\
\hline Peak Frequency & $>8.0 \mathrm{~Hz}$ & $4.5 \mathrm{~Hz}-8.0 \mathrm{~Hz}$ & $0.5 \mathrm{~Hz}-4.0 \mathrm{~Hz}$ \\
Peak Amplification Factor & $>7.5$ & $4.0-7.5$ & $1.5-4.0$ \\
Site Vulnerability Index & $>140$ & $80-40$ & $10-70$ \\
Remarks & High Vulnerability & Intermediate Vulnerability & Low Vulnerability \\
\hline
\end{tabular}

suggesting that sources are lying at deep inside the bedrock. It is, therefore, surface sources are the major controlling factors for $H / V$ peaks (Figure 6).

The site response (SR) in terms of peak amplification factor in the Pakyong area varies from 1.47 to 11.49 (Figure 6). The highest amplification value is observed at PK17 (North Kartoke, near Kartok/Gampa), with its $A_{\max }$ value as 11.79 , and is located in the north-western part of airport boundary. Amplification values ranging from 7.5 and above are categorized under the highly vulnerable Zone I which is observed at central portion of airport area trending in NW-SE pattern. The whole proposed airport area is covered with Chlorite Phyllite with intercalation of quartzite. This high amplification in the airport area may be due to loose and thick soil cover associated with low frequency ranges from $0.6 \mathrm{~Hz}$ to $6.0 \mathrm{~Hz}$. Amplification values ranging from 4.0 to 7.5 are classified under Intermediate Zone II. These Intermediate values are observed near Simsing (PK01), Samsing (PK05), Tsalumthang (PK07), Naya Busti (PK21), Dikling (PK24), Upper Lusing (PK47) and Pachak (PK29). The intermediate values associated with high amplification zone at the central portion of the airport area showing frequency variation in the range of 4.0 to 8.0 , indicating continuous decrease of soil thickness in the same rock formation. Low amplification values were observed from 1.5 to 4.0. The low amplification zone is observed near Pakyong (PK-06) and extending to different locations passing through Dugalakha (PK-09), Gumpa (PK-13), Pirikilakha(PK-19), Dikiling (PK-20), Dumlakha (PK-22), Pacheykhani (PK27), Pachem (PK-30), Assam Lingzey Road (PK-34) and Pachey (PK-35), suggesting comparatively competent sub-surface conditions. The area near stations Dugalakha (PK09), Dikiling (PK20), Dumlakha (PK22), Pachem (P30), Pachey (PK35) and Namchepung (PK41) correspond to the lesser amplification factor at varying frequency, indicating the most competent sub-surface soil formations. Based on above observations, we interpret that the low amplification and high frequency may represent sub-surface formation of lesser thickness. In the present study, the site amplification ranges from 2.0 to 12.0 which are in unison to earlier study by [18] for which, the range of soil variation in site amplification $A_{\max }$ varies as $A_{\max }<2.5$ to $\geq 8.5$ for the state of Sikkim and surrounding area.

Peak frequencies observed in the Pakyong airport site found varied between $0.5 \mathrm{~Hz}$ and $12.0 \mathrm{~Hz}$ (Figure 7). The highest peak frequency value was observed at PK30 (Pachem), with $\mathrm{f}_{\max }$ value as $12.11 \mathrm{~Hz}$ on the south of Damlakha village. It is worth to mention that a landslide has reported to occur nearer to station 
PK30.

On the basis of peak frequency contour map (Figure 7), three frequency zones are identified. The highest frequency Zone I ranges from $7.5 \mathrm{~Hz}$ to $12.5 \mathrm{~Hz}$ associated with low amplification values represent lesser soil thickness. The high frequency zones are observed Pachem (PK30, $\mathrm{f}_{\max } 12.11 \mathrm{~Hz}$ ), Pachey (PK35, $\mathrm{f}_{\max }$ $11.86 \mathrm{~Hz}$ ), Pakyong (PK36, $\left.\mathrm{f}_{\max } 11.61 \mathrm{~Hz}\right)$, Pacheykhani (PK27, $\mathrm{f}_{\max } 11.21 \mathrm{~Hz}$ ), Dikling (PK20, $\left.\mathrm{f}_{\max } 10.80 \mathrm{~Hz}\right)$, and Raigaon $\left(\mathrm{PK}-18, \mathrm{f}_{\max } 10.61 \mathrm{~Hz}\right)$. The intermediate frequency Zone II ranges between $4.5 \mathrm{~Hz}$ to $8.0 \mathrm{~Hz}$, however, the low frequency Zone III ranges from $0.5 \mathrm{~Hz}$ to $4.0 \mathrm{~Hz}$. In the proposed airport area, the frequency ranges between $0.5 \mathrm{~Hz}$ to $7.5 \mathrm{~Hz}$ over chlorite phyllite with intercalation of quartzite.

The high values of peak frequency and peak amplification factor is inferred because of greater thickness of weathered zone at the particular site (Figure $6 \&$ Figure 7).

High value of vulnerability index is represented in the area of chlorite phyllite geology (Figure 8). High amplification zone associated with high vulnerability indices $(\mathrm{Kg})$ is found in the central portion of then proposed airport area trending NW-SE. In other part of the study area the vulnerability index is low in comparison with the airport area.

In the proposed Pakyong airport site, high amplification values associated with high vulnerability indices in central part of study, so as to reduce the impact of amplification, compactness of loose soil and weathered rock. Based on distribution of Peak amplitiude, Peak frequency, and Site Vulnerability Index, we categorized our study area into three categories, such as Zone I, Zone II, and Zone III. Peak amplification and the corresponding peak frequency values were quantified at every station using Nakamura method. Site vulnerability index was also prepared to ascertain the degree of damage to infrastructures in these zones. The risk vulnerability of zones are varying as Zone I $>$ Zone II $>$ Zone III. It was found that the study area is conspicuously associated with site amplifications variability from 2.0 to 12.0 with that of corresponding peak frequency from $0.5 \mathrm{~Hz}$ to $12.5 \mathrm{~Hz}$. The anomalous sub-surface formation with its high amplification corresponds to the centre of the Pakyong airport site having conspicuous trend in NW-SE direction, which in turn suggests the existence of the geological formations of Chlorite Phyllite with intercalation of quartzite beneath the centre of the Pakyong airport site. The high amplification in the proposed airport area may be due to presence of intrusive bodies embedded with loose and thick soil cover associated with low frequency ranges $0.6 \mathrm{~Hz}$ to $6.0 \mathrm{~Hz}$. We infer that high vulnerability index corroborates with the conspicuous trend of the sub-surface intrusive bodies with loose and thick soil cover having similar trend of NW-SE direction in the central part of the Pakyong airport site having high variability with similar pattern to that of amplification factor in and around Pakyong airport area. These observations indicate that the Zone I has the highest vulnerability whilst those of other zones associated with comparatively compact parts of the subsurface materials have less amplification, suggesting less thick soil cover 
in the study area guarded by both high and low amplified zones of sub-surface formations. It is imperative to mention that for requisite engineering solutions may help minimizing the impact of earthquake shaking by reducing the extent of amplification of the sub surface formations through enhancement of the relative strength of the soft sediments underlying the Pakyong airport site for development of risk resilient infrastructural facility for the Sikkim state of India.

\section{Concluding Remarks}

Sustainability of structures is ensured by adopting risk resilient measures at the time of constructing infrastructures such as endeavour taken care of using sound buildings design codes, which can be generated through seismic microzonation study of the site. The Pakyong site is conspicuously guarded by two different sub-surface formations with the highest amplification factor to its NW and the moderate amplification factor to its NE. It is interesting to note that the central portion of the airport site is associated with high amplification factor as well as moderate to high site vulnerability index that corresponds to lose/soft soil formation of lesser strength that may have a greater impact during earthquake shaking. In order to develop risk resilient Pakyong airport as the vital infrastructural facility for Sikkim, India, robust engineering solutions might have been applied.

\section{Acknowledgements}

The author (OPM) is thankful to the team of Geologists and Geophysics, NER Geological Survey of India for which Site Response Study conducted by the Geophysical team under OPM as the Party Chief for Pakyong airport site during service to Geological Survey of India (CHQ), Kolkata. The author is thankful to Director General Geological Survey of India and Deputy Director General (Geophysics) for entrusting OPM to take up this investigation outside the FSP along with his team treating it as one of the challenging missions of completing a component of seismic microzonation. Reinterpretation of the reanalyzed high-quality data by authors is taken up using ArcGIS platform at National Centre for Seismology, Ministry of Earth Sciences, New Delhi is gratefully acknowledged. Authors are thankful to the Secretary, MoES; and Director (NCS-MoES) for encouragement and motivation to conduct the quality interpretation based on quality analyses of data. Authors are thankful to the anonymous reviewers and R. Wong, the Editor-in-Chief and entire editorial team to help the manuscript improved significantly.

\section{Conflicts of Interest}

The authors declare no conflicts of interest regarding the publication of this paper.

\section{References}

[1] Singh, O.P., Choudhuri, S.N. and Gaonkar, S.G. (2007) Site Response Studies in the 
Eastern Part of Guwahati City (Assam) Using Ambient Seismic Noise Analysis. Indian Minerals, 61, 141-148.

[2] Choudhuri, S.N., Singh, O.P. and Majumdar, R.K. (2011) Site Response Studies in Agartala Agglomeration. Natural Hazards, 59, 329-345.

https://doi.org/10.1007/s11069-011-9759-y

[3] Mohd, I., Bhol, L., Kumar, V., Mishra O.P., Chakrabortty, G.K., Chandrasekhar, S.V.N., Ram, B., Selinraj, A. and Luitel, S.K. (2014) A Report on Site Specific Study of Proposed Pakyong Airport Area, Sikkim, GSI.

[4] Mishra, O.P., Chakrabortty, G.K., Singh, O.P., Ghosh, D.C., Mukherjee, K.K. and Das, P.C. (2009) Interim Report on Seismogenesis in the Sikkim-Darjeeling Himalayas and Assimilation of Dynamic Snap Shots of the Regions: Future Vulnerability, $14 \mathrm{p}$.

[5] Mishra, O.P., Chakrabortty, G.K., Mukherjee, K.K., Singh, O.P., Ghosh, D.C. and Das, P.C. (2010) A Final Report on Seismogenesis in the Sikkim-Darjeeling Himalayas and Assimilation of Dynamic Snap Shots of the Regions: Future Vulnerability, $55 \mathrm{p}$.

[6] Das Gupta, S., Ganguly, J. and Neogi, S. (2004) Inverted Metamorphic Sequences in the Sikkim Himalayas: Crystallisation History, P-T Gradient and Implications. Journal of Metamorphic Geology, 22, 395-412. https://doi.org/10.1111/j.1525-1314.2004.00522.x

[7] Ray, K.K. (1989) On the Problems of Lithostratigraphic Classification of the Deformed Daling Group, Its Equivalents and Related Rocks of Himalayas. GSI Special Publication No. 22, 1-4.

[8] Acharya, S.K. (1989) The Daling Group, Its Nomenclature, Tectonostratigraphy and Structural Grain: With Notes on Their Possible Equivalents. GSI Special Publication No. 22, 5-13.

[9] Choudhuri, S.N., Singh, O.P., Mishra, O.P. and Kayal, J.R. (2008) Microzonation Study from Ambient Noise Measurement for Assessing Site Effects in Krishnagar Area and Its Significance with the Damage Pattern of Ms 4.3 of the 24th September, 1996 Earthquake, Special Issue. Indian Minerals, 61, 183-192.

[10] Anbazhagan, P., Thingbaijam, K.K.S., Nath, S.K., Kumaran, J.N. and Sitharam, T.G. (2010) Multi-Criteria Seismic Hazard Evaluation for Bangalore City, India. Journal of Asian Earth Sciences, 38, 186-198. https://doi.org/10.1016/j.jseaes.2010.01.001

[11] Mohanty, W.K., Walling, M.Y., Nath, S.K., Mitra, S. and John, A. (2009) Microtremor Survey in Talchir, India to Ascertain Its Basin Characteristics in Terms of Predominant Frequency by Nakamura H/V Ratio Technique. Engineering Geology, 106, 123-132. https://doi.org/10.1016/j.enggeo.2009.03.013

[12] Mohanty, W.K., Rajesh, P., Suresh, G., Shukla, A.K., Walling, M.Y. and Srivastava, J.P. (2009) Estimation of Coda Wave Attenuation for the National Capital Region, Delhi, India, Using Local Earthquakes. Pure and Applied Geophysics, 166, 429-449. https://doi.org/10.1007/s00024-009-0448-7

[13] Mandal, H.S., Shukla, A.K., Khan, P.K. and Mishra, O.P. (2013) A New Insight into Probabilistic Seismic Hazard Analysis of Central India. Pure and Applied Geophysics, 170, 2139-2161. https://doi.org/10.1007/s00024-013-0666-X

[14] Nath, S.K., Thingbaijam, K.K.S., Vyas, J.C., Prakash Dev, S.M.S. and Sengupta, P. (2010) Macroseismic-Driven Site Effects in the Southern Territory of West Bengal. Seismological Research Letters, 81, 480-487. https://doi.org/10.1785/gssrl.81.3.480

[15] Nath, S.K. and Thingbaijam, K.K.S. (2010) Assessment of Seismic Site Condition: A Case Study from Guwahati City, Northeast India. 
https://doi.org/10.1007/s00024-010-0197-7

[16] Nakamura, Y. (1996) Real Time Information Systems for Seismic Hazards Mitigation UrEDAS, HERAS, PIC. Quarterly Report of the Railway Technical Research Institute, 37, 112-127.

[17] Nakamura, Y. (2000) Clear Identification of Fundamental Idea of Nakamura's Technique and Its Applications. The 12 th World Conference on Earthquake Engineering, Auckland, New Zealand, 30 January-4 February 2000.

[18] Nath, S.K., Singh, K.K., Thingbaijam, K.K.S. and Roy, A. (2008) Earthquake Hazard in Northeast India-A Seismic Microzonation Approach with Typical Case Studies from Sikkim Himalaya and Guwahati City. Journal of Earth System Science, 117, 809-831. https://doi.org/10.1007/s12040-008-0070-6 